\title{
A Comparison of the Occurrence of Very-Low-Latitude Pi 2 Pulsations with Magnetic-Field and Energetic-Particle Flux Variations (30-300 keV) at Geosynchronous Altitudes
}

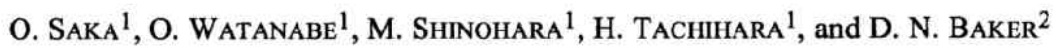 \\ ${ }^{1}$ Department of Earth and Planetary Sciences, Kyushu University, Fukuoka 812-81, Japan \\ ${ }^{2}$ Laboratory for Atmospheric and Space Physics, University of Colorado, Boulder, Colorado, 80309, U.S.A.
}

(Received September 11, 1995; Revised January 8, 1996; Accepted January 10, 1996)

\begin{abstract}
The occurrence of Pi 2 pulsations (20-150 s) at very-low-latitude stations is compared with the energetic-particle andmagnetic-field variations at geosynchronous orbit during the PROMIS ( $P$ olar $R$ egion and Outer Magnetosphere International Study) period (March 10-June 16, 1986). Ground magnetometer data from Huancayo, Peru (dip equator, $\left.75^{\circ} \mathrm{W}\right)$, and Kuju, Japan $\left(L=1.2,135^{\circ} \mathrm{E}\right)$, are utilized to monitor the magnetic pulsations, while the particles (electron, 30-300 keV; proton, 145-560 keV) and magnetic ficlds in space are monitored by geosynchronous satellites S/C1982-019, S/C1984-129, S/C1984-037, GOES-5, and GOES-6. Of $175 \mathrm{Pi} 2$ events surveyed during the PROMIS period, 110 events are accompanied by electron flux enhancement, and 51 events have a concurrent onset of the field-aligned current (FAC). The FAC events correlated with ground $\mathrm{Pi} 2$ pulsations indicate a local time change in polarities. If currents are assumed to flow along the field lines tailward of the geosynchronous orbit, the polarities are upward in the premidnight sector and downward in the postmidnight sector. We classified Pi 2 events in the nightside sector in several different ways. The results imply that if Pi 2 events in the present study can be assumed to be of substorm origin, then $47 \%$ of $\mathrm{Pi} 2$ events occur in regions close to geosynchronous altitude.
\end{abstract}

\section{Introduction}

Pi 2 magnetic pulsations (damped oscillations with periods of 40-150 s) associated with substorm expansion onset have been widely investigated, and the basic morphological pictures were established in the 1960s and 1970s (Saito, 1969; Jacobs, 1970; Orr, 1973; Lanzerotti and Fukunishi, 1974; Southwood and Stuart, 1980; McPherron, 1980). Pi 2 magnetic pulsations at high latitude $(L>4)$ on the nightside have generally been interpreted to be a transient standing resonance of the auroral field line excited at substorm expansion onset (Maltsev et al., 1974; Saito et al., 1976; Olson and Rostoker, 1977; Kuwashima, 1978) or to be oscillating localized field-aligned currents (FACs) in the substorm current wedge connected to the head of the westward traveling surge (Pashin et al., 1982; Lester et al., 1983; Samson and Rostoker, 1983; Sakurai and McPherron, 1983; Gelpi et al., 1987; Glassmeier, 1988; Glassmeier et al., 1988). Pi 2 events and low-energy particle flux enhancements at geosynchronous altitudes are correlated at a very high significance level and both signatures are considered to be effective indicators of the substorm expansion onset (Yeoman et al., 1994; Saka et al., 1994). Accordingly, Pi 2 pulsation is supposed to be related largely to the dynamics of the energetic particles in the nightside magnetosphere, where a local production of the hot plasmas by particle injection, and associated change of the field line configuration in the midnight sector during substorm expansion onset may introduce complex characteristics of the plasma dynamics, and hence those processes might give rise to a diverse, and sometimes controversial interpretation of the mechanisms of Pi 2 pulsations (e.g., Baumjohann and Glassmeier, 1984).

Pi 2 pulsations at middle and low latitudes have been suggested to originate from a field line oscillation at the plasmapause (Lanzerotti and Fukunishi, 1974; Stuart, 1974; Orr, 1975; Saito et al., 1976) or from magnetic impulsive disturbances launched in the near-Earth plasma sheet in association with a tail 
current disruption (Yumoto et al., 1989). Pi 2 pulsations at low latitudes $(L<2)$ are suggested to appear simultaneously in an area covering a wide local time in association with the onset of substorm expansion (Saito and Matsushita, 1968; Orr and Barsczus, 1969; Stuart and Barsczus, 1980; Sutcliffe and Yumoto, 1989). Pulsation signals launched in the nightside magnetosphere are assumed to propagate across the magnetosphere as a compression mode down to low latitudes and to fill the inner magnetosphere as a cavity mode (Allan et al., 1986; Kitamura et al., 1988; Lin et al., 1991; Sutcliffe and Yumoto, 1991; Itonaga et al., 1992; Takahashi et al., 1992). For such global characteristics, low-latitude Pi 2 pulsations are utilized for the purpose of identification of substorm onsets in the magnetosphere.

In this report, we examined the magnetic field and particle (electron, 30-300 keV; proton, 145-560 $\mathrm{keV}$ ) data in space acquired in the nightside sector at $L=6.6$ during the occurrence of $\mathrm{Pi} 2$ pulsations on the ground, and investigated correlated signatures to the ground Pi 2 onset that appeared in the particle and field line data in the geosynchronous orbit. We classified the ground Pi 2 events into four types according to the correlation with the satellite signature, and discussed the origin of the pulsations.

\section{Observations}

\subsection{Energetic-particle injections}

First, we look at the day-to-day variation of ground activity for low-latitude pulsations in the context of energetic-particle variations at geosynchronous altitude. The first example (March 25, 1986) is presented in Figs. 1 and 2, which show $24 \mathrm{~h}$ of data from charged particle analyzers (CPA; 30-300 keV for the electrons; $145-560 \mathrm{keV}$ for the protons) on board geosynchronous satellites S/C1982-019, S/C1984-129, and S/C1984-037 along with concurrent ground pulsation data. The top three panels in Fig. 1 show electron flux measurements from three geosynchronous satellites separated by 7 to $8 \mathrm{~h}$ of local time (Higbie et al., 1987). Local midnight for each satellite is marked by a solid triangle. Together, either of the satellites monitor the nightside sector that extends $\pm 4 \mathrm{~h}$ from local midnight. Ground observations were made at Huancayo (dip equator, $\left.75^{\circ} \mathrm{W}\right)$ and $\mathrm{Kuju}\left(L=1.2,135^{\circ} \mathrm{E}\right)$ by fluxgate magnetometers with time and amplitude resolutions of $0.03 \mathrm{nT}$ (Saka and Tachihara, 1986; Kitamura et al., 1988; Saka et al., 1988). Fluxgate magnetometer data filtered in the spectral bands of 20-100 s are plotted in the lower part of Figs. 1 and 2. Local midnight and local noon for the stations are marked by solid and open triangles, respectively. Major electron flux enhancement events detected by satellites in the midnight sector are indicated by arrows $\mathrm{A}$ through $\mathrm{K}$. The plots of filtered ground magnetometer data show that pulsation events appear in the leading edge of the electron flux enhancement labeled $\mathrm{C}$ through $\mathrm{K}$ or in the enhanced flux intervals labeled $\mathrm{A}$ and $\mathrm{B}$. The correspondence becomes less clear for the satellites in the dayside sector, as the electron cloud might diffuse during the dayside drift by the velocity dispersion effect (Ejiri, 1978 ) or by the trajectory modification in non-dipole field (Reeves, 1990). In the figure, many smaller impulsive events above magnetometer noise level were recorded, e.g., peak-to-peak amplitude less than $0.5 \mathrm{nT}$, some of which in the day time might be from local disturbances in the Equatorial Electrojet current or in SQ current system and some of which in the night time could be signals from the nightside magnetosphere. Because those smaller amplitude events did not show a clear correspondence to the night side particle enhancement, we did not select them as an event in the present report.

In Fig. 2, we look at the correlation of the occurrence with the proton flux enhancement. Figure 2 shows a tendency similar to that of the electron data, but some of the electron events with pulsation onsets (B, D, and E) have no proton flux enhancements. The probability of particle detection by satellite would be related to particle energy, because the radial distance of the earthward boundary of the injected particles increases with increasing particle energy (Ejiri, 1978). Discrepancies in the occurrences of electron and proton events are attributable to the different energy ranges of the respective particle detectors. Electron flux enhancements detected in the nightside sector are highly correlated with the occurrence of ground pulsations, irrespective of the local time of the ground station. We show in Fig. 3 the other example (April 12,1986 ), in which a train of seven electron flux enhancements is detected by the satellite at the midnight sector (2000-2300 LT). The ground station (Huancayo) was then located in the 0100-0400 LT sector and 


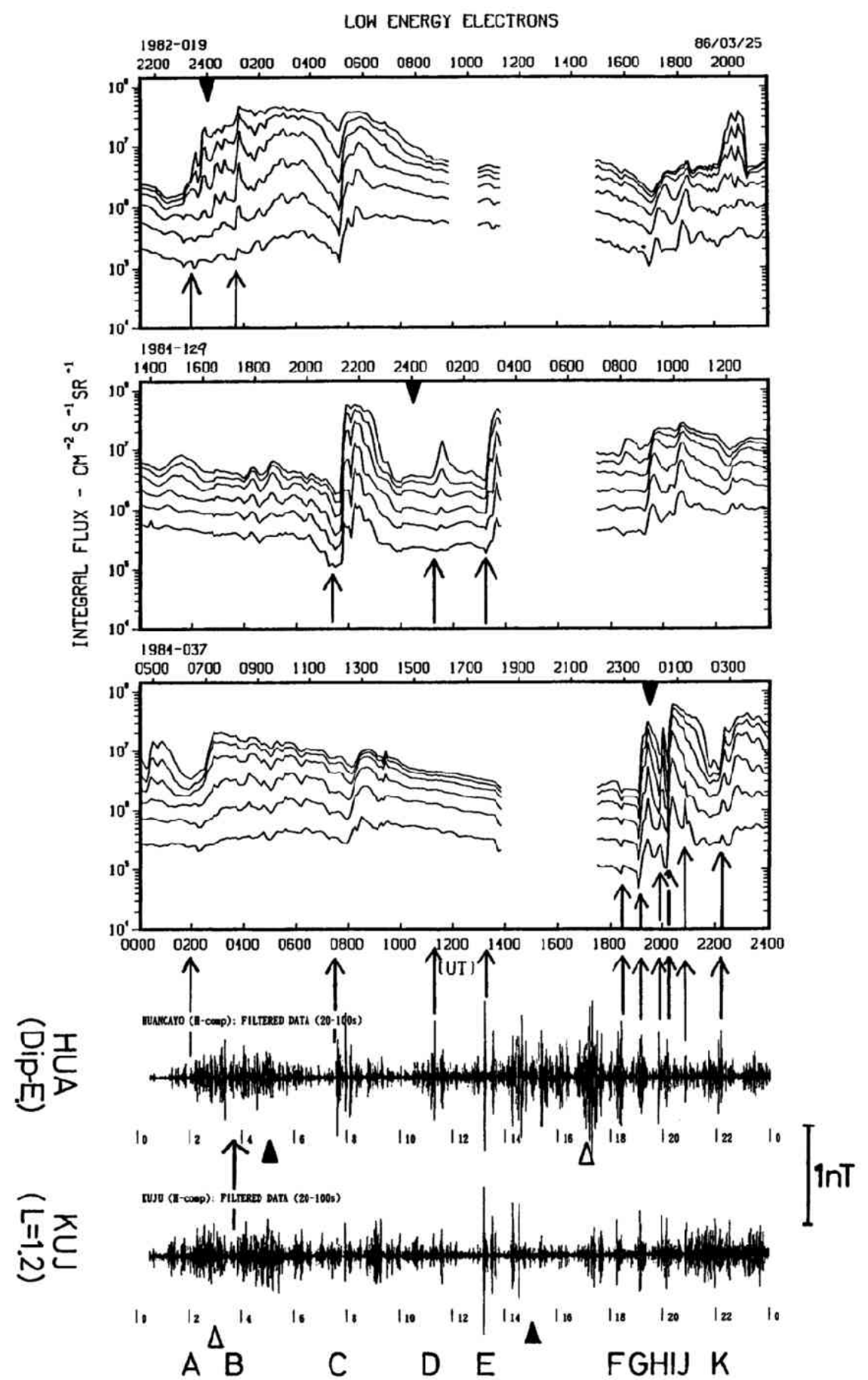

Fig. 1. Twenty-four hour (March 25, 1986) plots of electron flux data (30-300 keV) in space and magnetic pulsations on the ground. The upper three panels show the electron flux obtained by geosynchronous satellites (S/C1982-019, S/C1984-129, and S/C1984-037) (reproduced from Higbie et al., 1987). The satellite local midnight position is marked by a solid triangle. The lower two traces are ground pulsations bandpass filtered through 20-100 s. The station local midnight (noon) is marked by a solid (open) triangle. Vertical bars A through $\mathrm{K}$ indicate the onsets of electron flux enhancements and are correlated to ground pulsation activity (see text). 


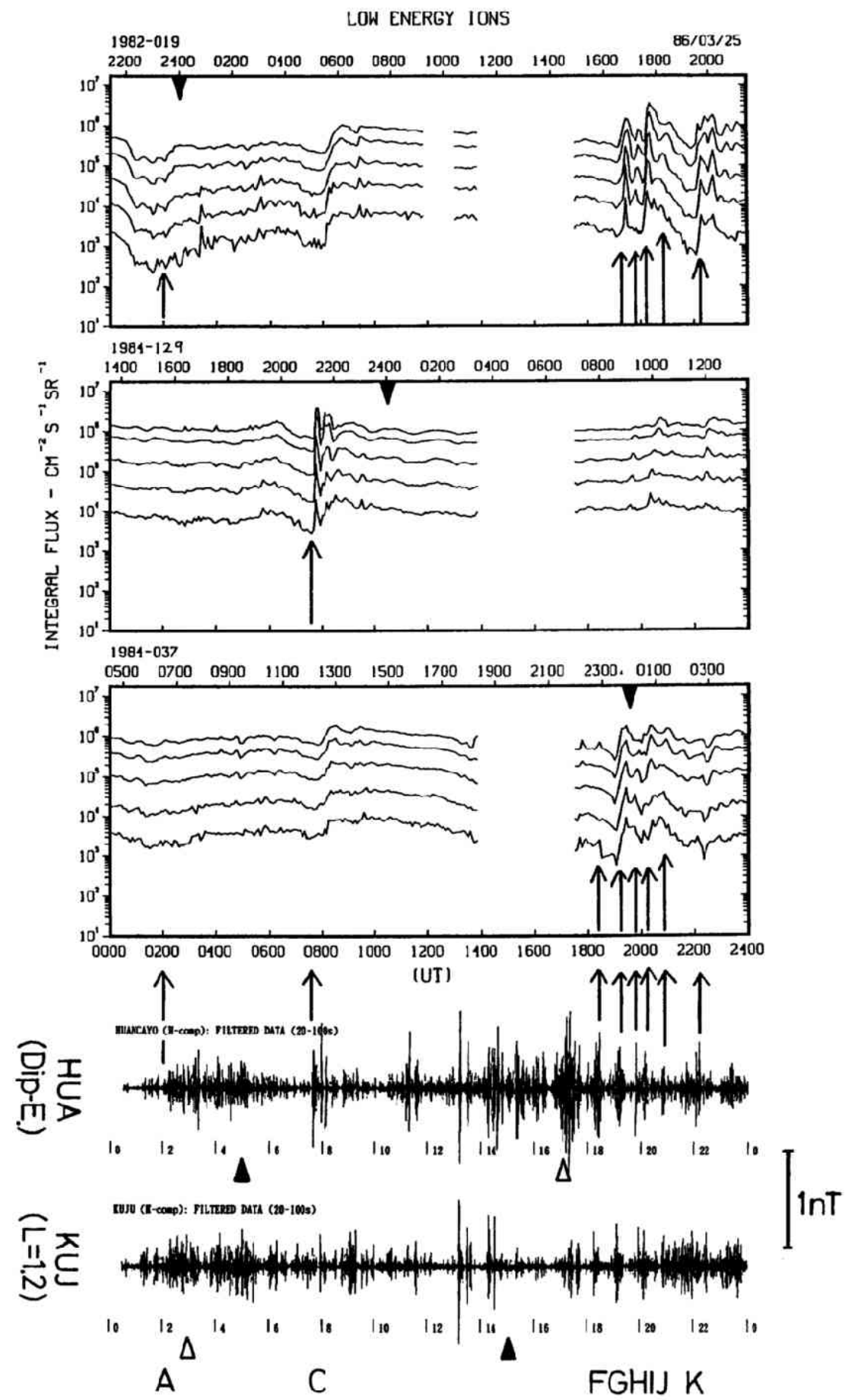

Fig. 2. Same as Fig. 1 but for proton flux data $(145-560 \mathrm{keV})$. Note that electron events with pulsation activity $(\mathrm{B}, \mathrm{D}$, and E) have no corresponding proton events (see text). 


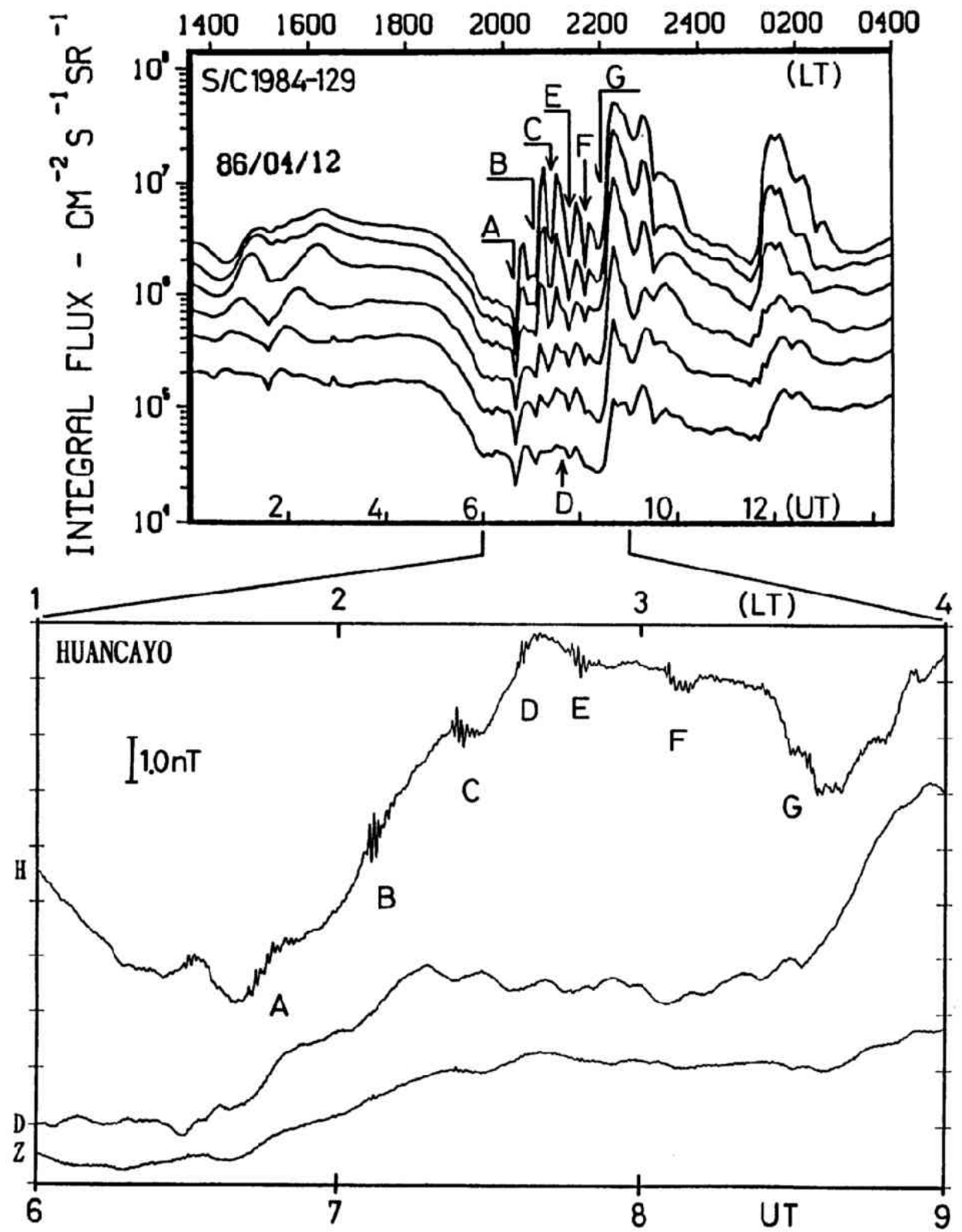

Fig. 3. Successive occurrences of electron flux enhancement in the nightside sector (S/C1984-129) and concurrent onset of $P i$ 2 train on April 12, 1986. The leading edge of the electron flux enhancement labeled A through $\mathrm{G}$ is marked by vertical bars in the flux data. The local times of the two locations are shown at the top of each panel.

shows seven impulsive pulsations (labeled A through G) at the positive gradient of the respective flux enhancements. The one-to-one correspondence between particle injection and pulsation onset is prominent as a whole for the impulsive pulsations and this relation is discussed below. We presented this period to show the occurrence of the impulsive pulsations and the background change of the $H$ component referred to as positive bay. The positive bay started at 0640 UT in association with the pulsation labeled A and increased the amplitude of the $H$ component until 0739 UT, afterwards the amplitudes decreased by the 


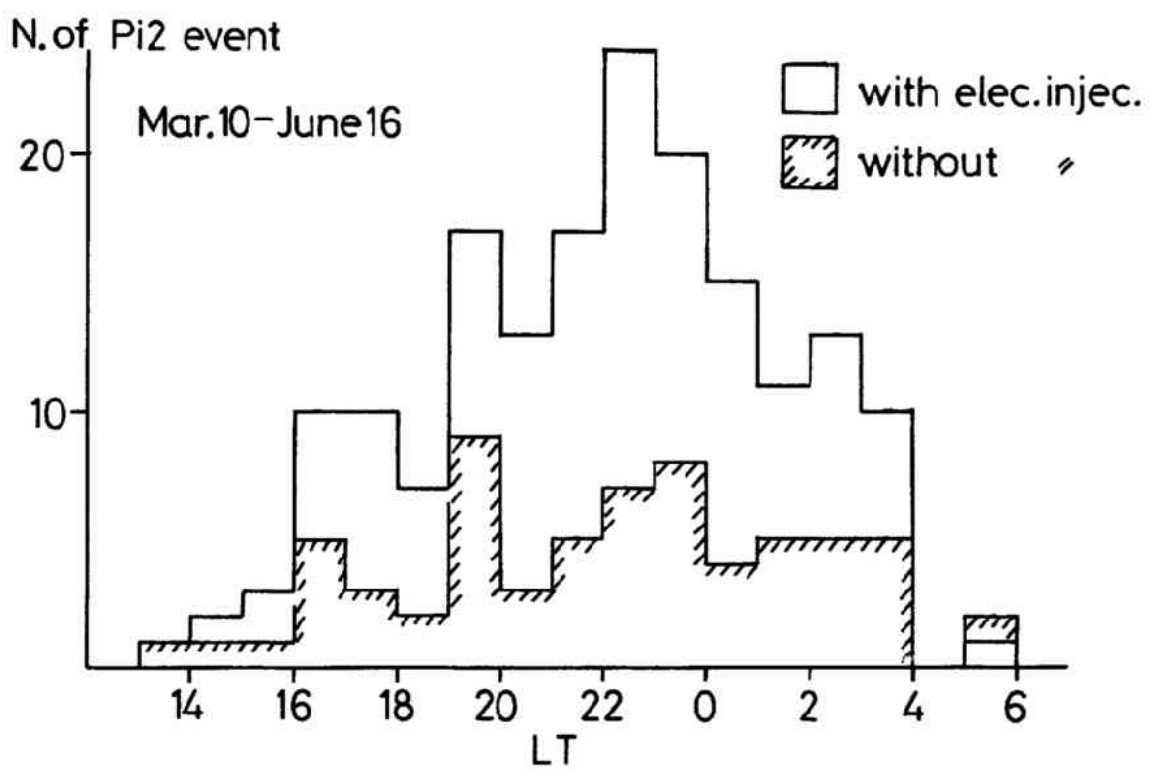

Fig. 4. Local time distribution of Pi 2 events accompanied (open area) and not accompanied (hatched area) by electron flux enhancement during the PROMIS period.

end of the pulsation labeled $\mathrm{G}$. Right after $\mathrm{G}$ event, the positive bay started again with wave activities of less clear wave forms. The $A E$ index for this period indicates small fluctuations around $200 \mathrm{nT}$ with no significant correlation with each of the pulsation, then the large shift of the $A E$ level $(500 \mathrm{nT})$ was attained after $\mathrm{G}$. In below, we discuss the corresponding field line signature in space for this particular periods by referring to the magnetic field data obtained by GOES-6 satellite in the midnight sector.

Huancayo magnetometer data during the PROMIS period (March 10-June 16, 1986) were surveyed, and impulsive pulsation events with peak-to-peak amplitudes larger than $0.6 \mathrm{nT}$ were selected by visual inspection of the filtered (20-600 s) data for the purpose of statistical study of the particle association discussed above. Because impulsive pulsation events in the morning sector tend to be masked by continuous background pulsation activity probably from Equatorial Electrojet current, events in the afternoon to nightside sectors were selected. They distributed over a wide local time (1300-0700 LT), with peak occurrence at $2200 \mathrm{LT}$. The duration of the event is typically $15 \mathrm{~min}$, but can sometimes be as long as $30 \mathrm{~min}$ or as short as $3 \mathrm{~min}$. Although the events were not selected in terms of spectral periods, they fall into the spectral range of $60-200 \mathrm{~s}$. We believe that the events selected are classified as $\mathrm{Pi} 2$ pulsations. Of 175 events thus chosen, 149 (85\%) occurred in the nightside sector (1800-0500 LT), and the other occurred in the afternoon sector (1300-1700 LT). CPA data from one of three geosynchronous satellites in the nightside sector were surveyed to find the onsets of electron flux enhancements during the Pi 2 pulsation events. A flux enhancement (in at least one of six channels) by more than a factor of 5 was identified as a flux event. Thus, in Fig. 4, Pi 2 pulsation events are classified as events with flux enhancements and events without enhancements. We found that 110 events $(63 \%)$ were accompanied by electron flux enhancements with less local time dependence.

\subsection{FACs}

Magnetic field data at geosynchronous altitudes during the ground campaign were obtained by fluxgate magnetometers on board GOES-5 and GOES-6 satellites at $75^{\circ} \mathrm{W}$ and $105^{\circ} \mathrm{W}$ longitudes. Because magnetic local times of the satellites are close to the local time of the ground station $\left(75^{\circ} \mathrm{W}\right)$, the satellite data can provide geomagnetic signatures at $L=6.6$ during low-latitude Pi 2 events in nearby 

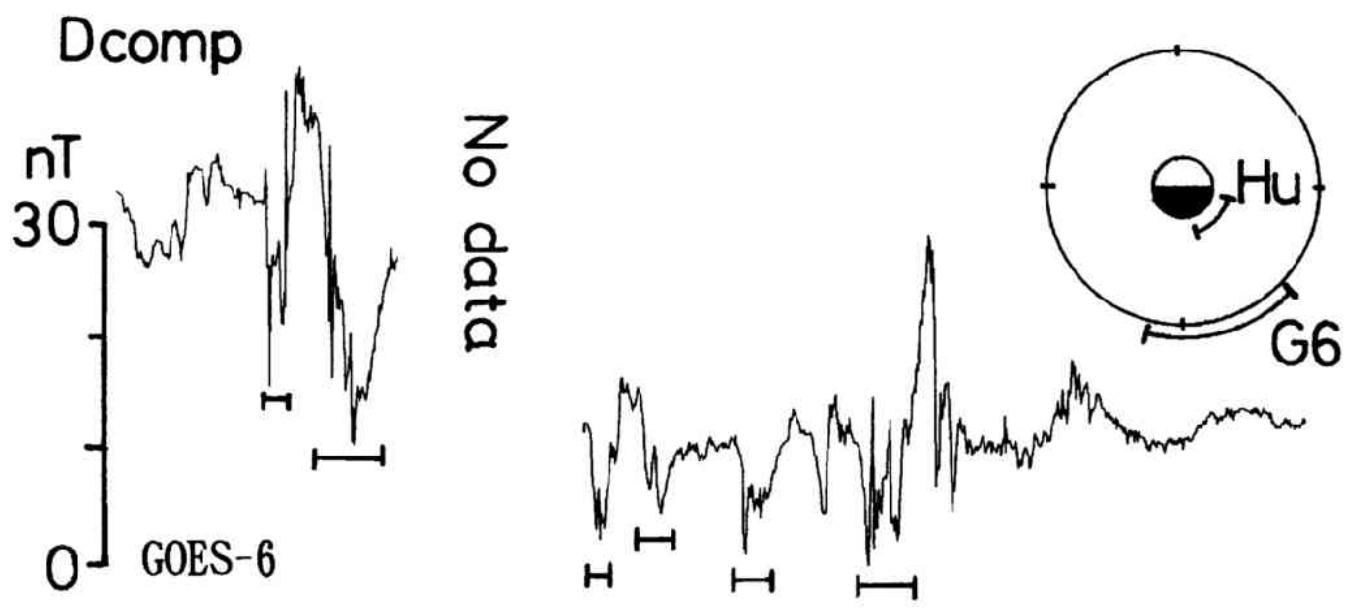

6

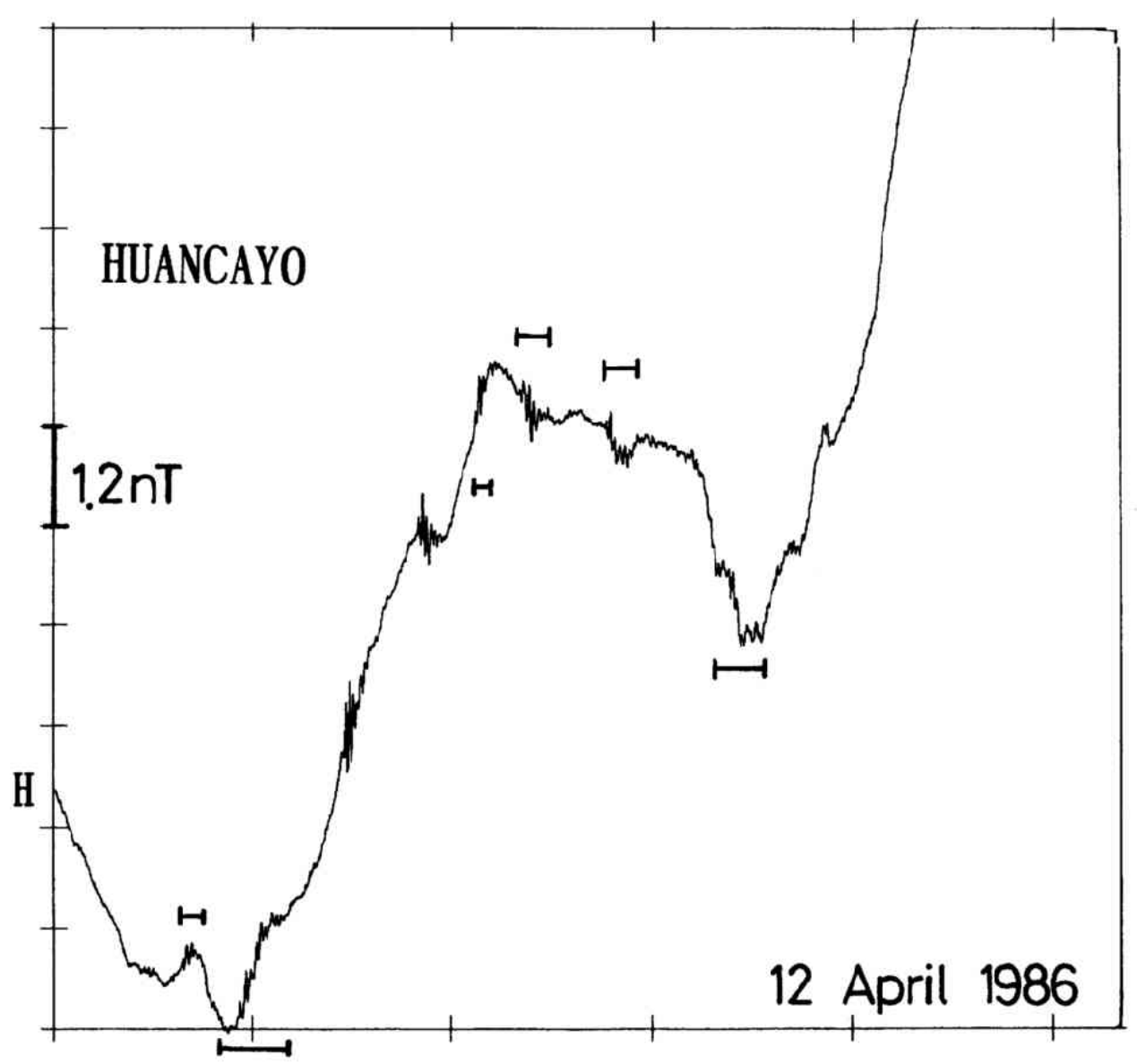

Fig. 5. Pi 2 train on April 12,1986, and concurrent magnetic field variations at conjugate geosynchronous orbit (GOES-5). The azimuthal component (positive eastward) that is supposed to represent field-aligned current activity is presented. The ground station location and the satellite position during 0600-1000 UT are illustrated at upper right. 
sectors. We show in Fig. 5 the field variations from the GOES- 6 satellite $(2 \mathrm{~h}$ behind the ground station at Huancayo) during events in Pi 2 trains on April 12. This event was studied in the previous section to show the correlation with respect to the occurrence of the electron flux enhancement in space and development of the $A E$ index, and positive bays on the ground. Although the field variations are seen in all components $(H, D$, and $V$ ) ( $H$ is parallel to the Earth's dipole axis pointing northward, $D$ is orthogonal to $H$ and azimuthal east, and $V$ completes the Cartesian coordinate system nearly radially outward), we present only the azimuthal component, $D$. We can look at the one-to-one association of successive onsets of $\mathrm{Pi} 2$ events with negative spikes in the $D$ component (indicated by horizontal bars). In general, the negative excursions of the $D$ component are also associated with a temporal variation in field magnitude and field inclination, in which the field change is more or less transient, and the lifetime of the negative excursion is comparable to that of the ground Pi 2 packet. Despite the successive onsets of Pi 2, no significant development of field dipolarization can be seen in the $H$ component (not shown) until the end of the last Pi 2 packet (labeled G) at 0846 UT. Such an association was not clearly identified by the eastern satellite GOES $-5\left(75^{\circ} \mathrm{W}\right)$ in the early morning sector, which indicates that the field line disturbances associated with the Pi 2 onset are night side events. We suggest that the seven electron injections, though they accompanied the Pi 2 onset labeled A through G, would not contribute largely to the field line dipolarization in space (i.e., substorm onset), because the ground $A E$ index did not develop into a significant level. A close association between the onset of the $D$ component excursion and the onset of ground Pi 2 pulsations, as demonstrated above, often occurs when the ground-satellite pair is in the local time sector ranging from 1900 to $0400 \mathrm{LT}$. A characteristic to be noted in this association is the more or less concurrent onset of the first increase of the ground $H$ component of the Pi 2 pulsation and the development of the $D$-component excursion. The duration of the $D$-component excursion varies from event to event, but the excursion is not much longer than the lifetime of the Pi 2 event.

On the basis of the ground-satellite (Huancayo and GOES-5 pair) data set during the PROMIS period, we estimate an occurrence distribution of low-latitude Pi 2 events that are accompanied by the $D$-component deflection. The occurrence is shown in Fig. 6 as a function of local time; the distribution of whole

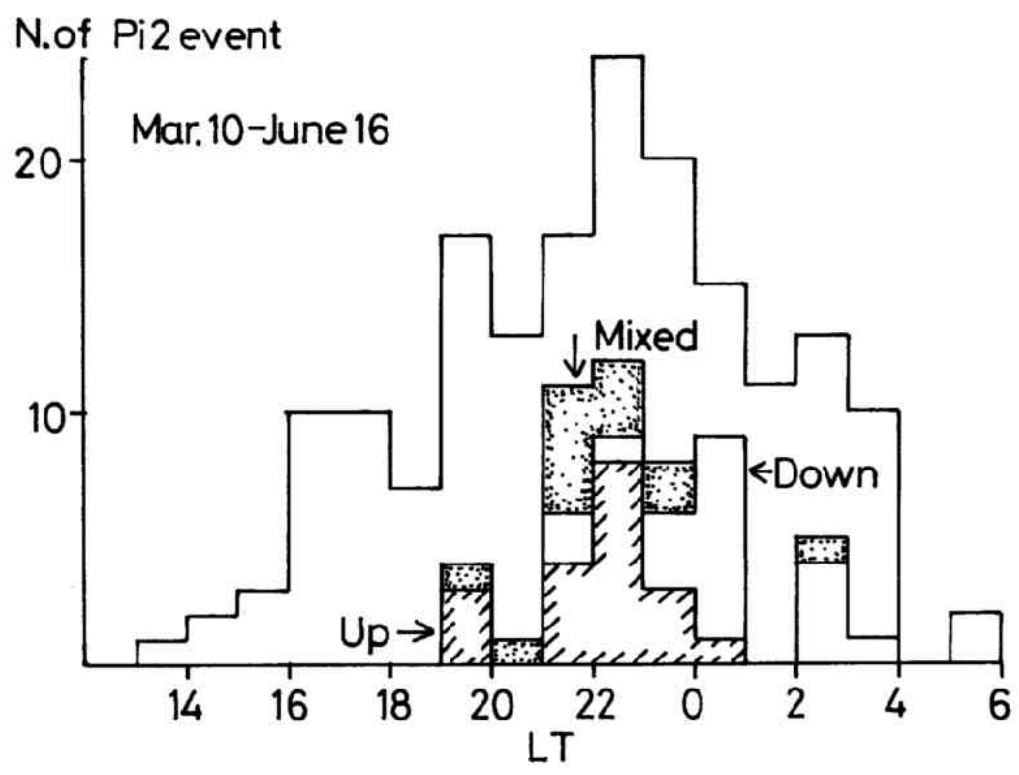

Fig. 6. Local time distribution of whole Pi 2 events (outer frame) and of Pi 2 events with field-aligned currents of upward (hatched), downward (open), and mixed (dotted) polarities. Field-aligned current events are surveyed by the conjugate satellite GOES-5. 
Pi 2 is also shown. Fifty-one Pi 2 events are accompanied by a $D$ excursion between 1900 and 0400 LT, these events are $36 \%$ of the total number of $\mathrm{Pi} 2$ events (140) observed in that local time sector. Events that are composed of highly mixed structures of the $D$ excursions are included as FAC events. Nevertheless, the excursion of the $D$ component for an event with a distinct polarity is predominantly eastward before $2300 \mathrm{LT}$ and westward after $2300 \mathrm{LT}$. If we suppose that the current source could be located tailward of the geosynchronous altitudes (Nagai, 1987), then the $D$-component excursions in the pre- and post-midnight sectors are caused by the upward (pre-midnight) or downward (post-midnight) FAC, the polarities are similar to the traditional region 1 current system.

The dipolarization of the Earth's fields as inferred by the increase in $H$-component strength at the satellite location is examined for Pi 2 events associated with FAC signatures (upward, downward or undistinguished polarities). Of 51 FAC events in the nightside sector (1900-0400 LT), 31 events (62\%) are accompanied by the dipolarization, and 16 of these 31 have time delays of as much as $5 \mathrm{~min}$. The dipolarization often ceases at the end of the Pi 2 packet. Of 51 events, 7 show a change to more taillike configurations in association with the onset of $\mathrm{Pi} 2$ pulsations.

\section{Discussion}

We determined the characteristics in the nightside sector of energetic-electron flux $(30-300 \mathrm{keV})$ and magnetic field variations at geosynchronous altitudes at the time of ground $\mathrm{Pi} 2$ pulsation events recorded at Huancayo, Peru (dip equator) during the PROMIS periods (March 10-June 16, 1986). Three different data sets were employed to examine the ground-satellite correlation. We looked for Pi 2 events in the Huancayo magnetogram when the ground station moved into the nightside sector(1900-0300 LT) and for electron flux enhancement events from one of the three geosynchronous satellites located in the midnight sector. Likewise, fluxgate magnetometer data were surveyed, but by a single ground-satellite pair (Huancayo and GOES-5) in the adjoining meridian $\left(75^{\circ} \mathrm{W}\right)$. In this way, we classified $140 \mathrm{Pi} 2$ events into groups with flux enhancement (64\%) and without flux enhancement (36\%) or into groups with FAC (36\%) and without FAC (64\%) (see Figs. 4 and 6). In order to see a correlation between two statistics obtained by different combinations of the data, both distributions during 2100-0100 LT are combined and summarized in Table 1 . Statistically, $47 \%$ of the Pi 2 events during midnight sector ( $2100-0100 \mathrm{LT})$ had both flux enhancement and FAC development, $21 \%$ had flux enhancement alone, $5 \%$ had FAC alone, and the remaining $26 \%$ gave no indication of either flux enhancement or FAC. Thus, it is suggested that $68 \%$ of the Pi 2 events are particle associated and $31 \%$ of the Pi 2 events are not particle associated.

Development of FAC and onset of particle injections in the nightside magnetosphere are thought to be associated with the plasma dynamics common to substorm onset (e.g., Nagai, 1987, and references therein for FAC signature; Baker et al., 1987, for particle injection). Accordingly, the particle-associated Pi 2 events with FAC activity are possibly caused by substorm activity, though those events may not always lead to enhancement of the $A E$ index or to the field dipolarization in space. Since particles that are trapped and carried eastward are collected by satellites in the downstream (morning) sector while a FAC event is observed only by a nearby satellite, we suppose that a particle enhancement event might be detected more often than a FAC event. Moreover, FAC events tend to be less counted, because upward and downward currents cancel the FAC signature when the satellite was middle of the FAC current system.

Table 1. Classification of $76 \mathrm{Pi} 2$ events during $2100-0100 \mathrm{LT}$. No. (\%) of events.

\begin{tabular}{lcc}
\hline & $\begin{array}{c}\text { Particle-associated } \\
(n=52)\end{array}$ & $\begin{array}{c}\text { Non-particle-associated } \\
(n=24)\end{array}$ \\
\hline With FAC $(n=40)$ & $36(47 \%)$ & $4(5 \%)$ \\
No FAC $(n=36)$ & $16(21 \%)$ & $20(26 \%)$ \\
\hline
\end{tabular}


This effect could probably explain discrepancies between the occurrence probabilities of particleassociated events (68\%) and $\mathrm{FAC}$-associated events (52\%). If we can assume that ground $\mathrm{Pi} 2$ pulsations originate more or less from substorm activity, then events without both of the substorm signatures (flux enhancement and FAC) could be generated by plasma dynamics in a tailward region that is probably remote from the geosynchronous orbit, and those events with both the particle injection and the FAC activities $(47 \%)$ could occur in regions close to geosynchronous altitude.

The present results are consistent with the results obtained by Yeoman et al. (1994), who studied the correlation of the occurrence of mid-latitude $\mathrm{Pi} 2$ and of the particle injection at geostationary orbit, in which they identified that $73 \%$ of those events were accompanied by the injection events $(68 \%$ for our study). Furthermore, they identified that of 195 injection events, $63 \%$ of the injection events may not have a corresponding Pi 2 onset. Although, this correspondence was not examined in the present report, we feel that injections would have been accompanied by Pi 2 onset more often (see Fig. 1) during the PROMIS periods. Further studies are needed to clarify this discrepancy that may appear in two data sets, by taking account of the effects of the solar activity, and seasons that may affect the particle distributions and drift path in the equator.

We thank M. Ishitsuka and $\mathrm{O}$. Veliz of Instituto Geofisico der Peru for their efforts in acquiring magnetometer data at Huancayo. The authors thank NSSDC (GSFC/NASA) for the PROMIS data book series used in this research. GOES magnetometer data are supplied by National Geophysical Data Center, NOAA.

\section{REFERENCES}

Allan, W., S. P. White, and E. M. Poulter, Impulse-excited hydromagnetic cavity and field-line resonances in the magnetosphere, Planet. Space Sci., 34, 371-385, 1986.

Baker, D. N., P. R. Higbie, E. W. Hones, Jr., and R. D. Berian, High-resolution energetic particle measurements at $L=6.6,3$, Lowenergy electron anisotropies and short-term substorm predictions, J. Geophys. Res., 83, 4863-4868, 1987.

Baumjohann, W. and K. Glassmeier, The transient response mechanism and Pi 2 pulsations at substorm onset-review and outlook, Planet. Space Sci., 32, 1361-1370, 1984.

Ejiri, M., Trajectory traces of charged particles in the magnetosphere, J. Geophys. Res., 83, 4798-4810, 1978.

Gelpi, C., H. J. Singer, and W. J. Hughes, A comparison of magnetic signatures and DMSP auroral images at substorm onset: three case studies, J. Geophys. Res., 92, 2447-2460, 1987.

Glassmeier, K. H., Reconstruction of the ionospheric influence on ground-based observations, a short duration ULF pulsation event, Planet. Space Sci., 36, 801-817, 1988.

Glassmeier, K. H., W. Baumjohann, A. Korth, and P. Gough, High-latitude Pi2 pulsations, ELF intensity, and particle flux variations, A case study, Ann. Geophys., 6, 287-295, 1988.

Higbie, P. R., D. N. Baker, and E. W. Hones, Jr., Electron and ion data from the geosynchronous satellites 1982-019, 1984-037, and 1984-126, PROMIS Ser., vol. 6, National Space Science Data Center, NASA Goddard Space Flight Center, Greenbelt, Md., 1987.

Itonaga, M., T. Kitamura, O. Saka, H. Tachihara, M. Shimoizumi, and Y. Yoshikawa, Discrete spectral structure of low-latitude and equatorial Pi2 pulsation, J. Geomag. Geoelectr., 44, 253-259, 1992.

Jacobs, J. A., Geomagnetic Micropulsation, 176 pp., Springer, New York, 1970.

Kitamura, T., O. Saka, M. Shimoizumi, H. Tachihara, T. Oguti, T. Araki, N. Sato, M. Ishitsuka, O. Vrliz, and J. B. Nyobe, Global mode of Pi 2 waves in the equatorial region-Difference of Pi2 mode between high and equatorial latitudes, J. Geomag. Geoelectr., 40, 621-634, 1988.

Kuwashima, M., Wave characteristics of magnetic Pi 2 pulsations in the high latitude region, spectral and polarization studies, Mem. Natl. Inst. Polar Res., Series A, 15, 79, 1978.

Lanzerotti, L. J. and H. Fukunishi, Modes of hydromagnetic waves in the magnetosphere, Rev. Geophys., 12, 724-729, 1974.

Lester, M., W. J. Hughes, and H. J. Singer, Polarization patterns of Pi2 magnetic pulsations and the substorm current wedge, $J$. Geophys. Res., 88, 7958-7966, 1983.

Lin, C. A., L. C. Lee, and Y. J. Sun, Observations of Pi2 pulsations at a very low latitude $(L=1.06)$ station and magnetic cavity resonances, J. Geophys. Res., 96, 21105-21113, 1991.

Maltsev, Y. P., S. V. Leontyev, and W. B. Lyatsk, Pi2 pulsations as a result of evolution of an Alfven impulse originating in the ionosphere during a brightening of the aurora, Planet. Space Sci., 22, 1519-1533, 1974.

McPherron, R. L., Substorm associated micropulsations at synchronous orbit, J. Geomag. Geoelectr., 32, Suppl. II, SII57, 1980.

Nagai, T., Field-aligned currents associated with substorms in the vicinity of synchronous orbit, 2, Goes 2 and Goes 3 observations, J. Geophys. Res., 92, 2432-2446, 1987. 
Olson, J. V. and G. Rostoker, Latitudinal variation of the spectral components of auroral zone Pi2, Planet. Space Sci., 25, 663$671,1977$.

Orr, D., Magnetic pulsations within the magnetosphere: A review, J. Atmos. Terr. Phys., 35, 1-150, 1973.

Orr, D., Probing the plasmapause by geomagnetic pulsations, Ann. Geophys., 31, 77-92, 1975.

Orr, D. and H. G. Barsczus, Geomagnetic micropulsations, Pi2, at low latitudes, Planet. Space Sci., 17, 497-507, 1969.

Pashin, A. B., K. H. Glassmeier, W. Baumjohann, O. M. Raspopov, A. G. Yahnin, H. J. Opgenoorth, and R. J. Pellinen, Pi2 magnetic pulsations, aurora break-ups, and the substorm current wedge: A case study, J. Geophys., 51, 223-233, 1982.

Reeves, G. D., T. A. Fritz, T. E. Cayton, and R. D. Belian, Muiti-satellite measurements of the substorm injection region, Geophys. Res. Lett., 17, 2015-2018, 1990.

Saito, T., Geomagnetic micropulsations, Space Sci. Rev., 10, 319-412, 1969.

Saito, T. and S. Matsushita, Solar cycle effects on geomagnetic Pi2 pulsations, J. Geophys. Res., 73, 267-286, 1968.

Saito, T., T. Sakurai, and Y. Koyama, Mechanism of association between Pi2 pulsation and magnetospheric substorm, J. Atmos. Terr. Phys., 38, 1265-1277, 1976.

Saka, $\mathrm{O}$. and $\mathrm{H}$. Tachihara, A compact magnetometer data acquisition system with accurate chronometer, J. Geomag. Geoelectr., 38, 221-230, 1986.

Saka, O., T. Kitamura, M. Shimoizumi, T. Araki, T. Oguti, O. Veliz, and M. Ishitsuka, The effects of non-uniform ionosphere on the equatorial Pc pulsations, J. Geomag. Geoelectr., 40, 635-643, 1988.

Saka, O., O. Watanabe, and D. N. Baker, A comparison of occurrence of very low-latitude magnetic pulsations with magnetic field and energetic particle flux variations (30-300 keV) at geosynchronous altitude, Proceedings of 8th International Symposium on Solar Terrestrial Physics, Sendai, 107, 1994.

Sakurai, T. and R. L. McPherron, Satellite observations of Pi2 activity at synchronous orbit, J. Geophys. Res., 88, 7015-7027, 1983.

Samson, J. C. and G. Rostoker, Polarization characteristics of Pi2 pulsations and implications for their source mechanisms: influence of the westward traveling surge, Planet. Space Sci., 31, 435-458, 1983.

Southwood, D. J. and F. W. Stuart, Pulsations at the substorm onset, in Dynamics of the Magnetosphere, edited by S.-I. Akasofu, pp. 341-355, D. Reidel, Hingham, Mass., 1980.

Stuart, W. F., A mechanism of selective enhancement of Pi2's by the plasmasphere, J. Atmos. Terr. Phys., 36, 851-859, 1974.

Stuart, W. F. and H. G. Barsczus, Pi's observed in the daylight hemisphere at low latitudes, J. Atmos. Terr. Phys., 42, 487-497, 1980.

Sutcliffe, P. R. and K. Yumoto, Dayside Pi2 pulsations at low latitudes, Geophys. Res. Lett., 16, 887-890, 1989.

Sutcliffe, P. R. and K. Yumoto, On the cavity mode nature of low-latitude Pi2 pulsations, J. Geophys. Res., 96, $1543-1551,1991$.

Takahashi, K., S. Ohtani, and K. Yumoto, AMPTE CCE observations of Pi2 pulsations in the inner magnetosphere, Geophys. Res. Lett., 19, 1447-1450, 1992.

Yumoto, K., K. Takahashi, F. W. Menk, B. J. Fraser, T. A. Potemra, and L. J. Zanetti, Some aspects of the relation between Pil2 magnetic pulsations observed at $L=1.3-2.1$ on the ground and substorm-associated magnetic field variations in the nearEarth magnetotail observed by AMPTE CCE, J. Geophys. Res., 94, 3611-3618, 1989.

Yeoman, T. K., M. P. Freeman, G. D. Reeves, M. Lester, and D. Orr, A comparison of Pi2 pulsations and geostationary orbit particle injections as substorm indicator, J. Geophys. Res., 99, 4085-4093, 1994. 